\title{
Heat treatment cycle optimization for A707L5 copper-nickel steel
}

\author{
Carlo Mapelli' ${ }^{1}$ Silvia Barella1 , Andrea Gruttadauria1, Davide Mombelli ${ }^{1}$ \\ and Dario Ripamonti ${ }^{2}$ \\ 1 Sezione Materiali per Applicazioni Meccaniche, Dipartimento di Meccanica, Politecnico di Milano, \\ via La Masa 34, 20156 Milano, Italy \\ e-mail: carlo.mapelli@polimi.it \\ 2 Istituto IENI-CNR, Unità territoriale di Milano, via R. Cozzi 53, 20125 Milano, Italy
}

Key words:

A707L5; copper steel; $\varepsilon$-Cu; perlite; solution quenching; aging

Received 5 February 2015

Accepted 8 July 2015

\begin{abstract}
The mechanical properties of the A707L5 steel grade were studied as a function of the applied aging temperature. The results obtained are discussed on the basis of the microstructure analysis and precipitates were identified on the fracture surfaces observed by scanning electron microscopy assisted by a field emission gun (FEG-SEM). This steel grade appears to be particularly sensitive to the aging time-temperature, which significantly affected the precipitation phenomena. The annealing temperature and solution quenching involved in the thermal cycle significantly affect the perlite formation, the grain size and the $\varepsilon$-Cu precipitates that represent the main factors of influence ruling the mechanical properties.
\end{abstract}

$\mathrm{T}$ he present work is focused on a copper-nickel alloyed steel that exploits a strengthening mechanism involving precipitation like the HSLA [1-3] steel currently available on the market, but in this case the hardening effect is not associated with the formation of ceramic compounds but with the precipitation of a copper phase whose nucleation and growth is controlled by an applied thermal treatment and significantly affected by the aging modalities [4-6]. The studied steel is classified in the ASTM standard as A707L5 steel grade (Tab. 1).

The selection of this steel is particularly interesting for oil and gas applications; indeed, nickel addition allows improving the corrosion resistance and decreases the brittle transition temperature, improving the toughness of the steel. The fine precipitation of $\varepsilon$-Cu during an aging treatment does not induce any detrimental effects on toughness but it can cause grain boundary strengthening and a precipitation hardening effect [7-9].

The experimental trials performed aimed at stating the optimal heat treatment parameters in order to maximize the toughness and
Table 1. Chemical composition of A707L5 steel alloyed by $\mathrm{Ni}$ and $\mathrm{Cu}$ measured by Optical Emission Spectrometer (OES).

\begin{tabular}{ccccccc}
\hline$\% \mathrm{C}$ & $\% \mathrm{Si}$ & $\% \mathrm{Mn}$ & $\% \mathrm{Cr}$ & $\% \mathrm{Ni}$ & $\% \mathrm{Cu}$ & $\% \mathrm{~S}$ \\
\hline 0.07 & 0.25 & 0.7 & 0.9 & 1.5 & 1.3 & 0.25 \\
\hline
\end{tabular}

mechanical strength. The optimal combination for the operative parameters of the heat treatment was defined in order to satisfy the mechanical properties that are usually required for the application of this steel grade and the mechanical properties obtained are discussed on the basis of the microstructural characteristics.

\section{Experimental procedure}

ASTM A707L5 (Tab. 1) is a steel grade usually used for producing forged products.

Differential scanning calorimetry (DSC) was performed to define the transformation temperatures of the steel. The identification of the transformation temperature was carried out by imposing a heating rate of $0.35{ }^{\circ} \mathrm{C} / \mathrm{s}$ from room temperature up to $1000{ }^{\circ} \mathrm{C}$, followed by soaking at $1000{ }^{\circ} \mathrm{C}$ for $1000 \mathrm{~s}$ and cooling at a thermal rate of 

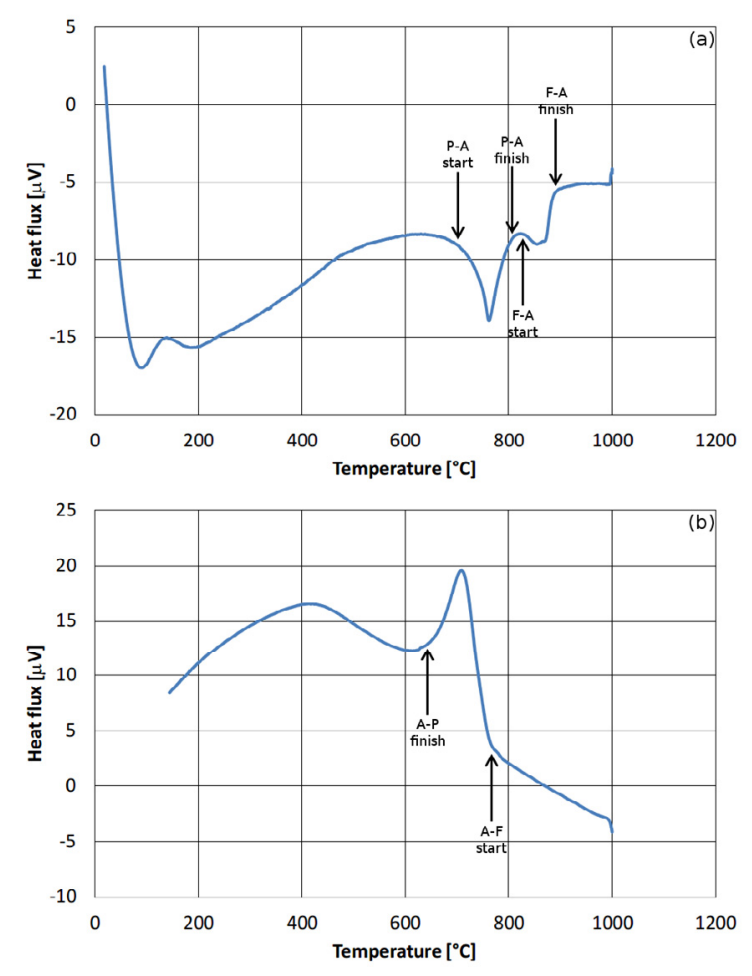

Fig. 1. Results of Differential Scanning Calorimetry (DSC) during the heating (a) and cooling steps (b). A: austenite; F: ferrite; P: perlite.

Table 2. Phase transformation temperature identified by DSC investigation during the heating and cooling steps.

\begin{tabular}{cc}
\hline \multicolumn{2}{c}{ Heating step } \\
\hline Perlite-Austenite transformation start & $697^{\circ} \mathrm{C}$ \\
Perlite-Austenite transformation finish & $808{ }^{\circ} \mathrm{C}$ \\
Ferrite-Austenite transformation start & $815^{\circ} \mathrm{C}$ \\
Ferrite-Austenite transformation finish & $885^{\circ} \mathrm{C}$ \\
\hline Cooling step \\
\hline Austenite-Ferrite transformation start & $775^{\circ} \mathrm{C}$ \\
Austenite-Perlite transformation finish & $640{ }^{\circ} \mathrm{C}$ \\
\hline
\end{tabular}

$-0.35^{\circ} \mathrm{C} / \mathrm{s}$ down to room temperature (Fig. 1 , Tab. 2).

The untreated material constituted two forged round bars $4.5 \mathrm{~m}$ in length and $0.25 \mathrm{~m}$ in diameter produced from a part of a cast ingot $1 \mathrm{~m}$ in length and $0.75 \mathrm{~m}$ in diameter. After the identification of the transformation phase temperatures, the heat treatment cycles were defined (Fig. 2, Tab. 3).

The $2 \mathrm{~T}$ cycle represents reference conditions obtained by normalization and aging, and these conditions were used for the comparison with the mechanical performances shown after the application of the solution quenching and the aging treat-

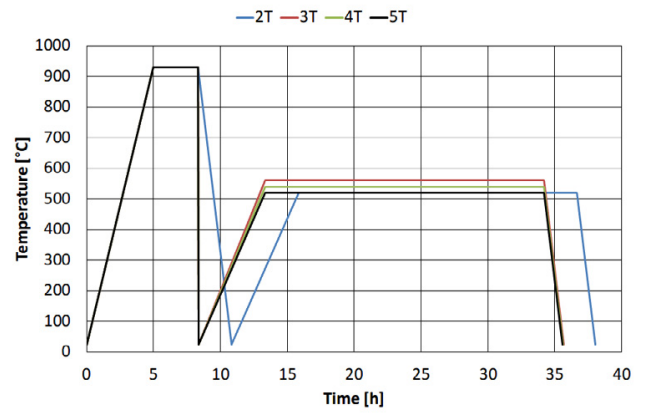

Fig. 2. Comparison among the different heat treatment cycles.

ments. All the specimens used for the tensile tests, the Charpy impact tests and the microstructural characterization were sampled from $62.5 \mathrm{~mm}$ depth from the surface of the forged bar. The mechanical characterization was performed by micro-hardness Vickers tests (using a $20 \mathrm{~g}$ load and $15 \mathrm{~s}$ dwell time) and tensile tests (ASTM E8/E8M) in order to measure the strength properties and steel ductility as a function of the applied heat treatments. The impact tests were performed on 3 specimens for each heat treatment and test temperature: $-60^{\circ} \mathrm{C},-75^{\circ} \mathrm{C},-90^{\circ} \mathrm{C}$ and $-105^{\circ} \mathrm{C}$. The tensile and Charpy impact tests were performed to optimize the aging temperatures to fit the minimum acceptable values and the mechanical characteristics usually required by users for the application of this steel grade (Tab. 4). The microstructural characterization was performed by Optical Microscopy $(\mathrm{OM})$ to reveal the structural constituents and the average grain size, that was measured according to ASTM E112.

The ground and polished specimens were etched with $5 \% \mathrm{HNO}_{3}$ and $95 \%$ ethanol solution for $5 \mathrm{~s}$. The electronic microscopy observation was performed by a field emission gun scanning electron microscope (FEG-SEM) used to characterize the nano-precipitates. The fracture surfaces investigated were obtained through the induction of intergranular fractures by an impact applied after the immersion of the sample in liquid nitrogen $\left(-196^{\circ} \mathrm{C}\right)$. The chemical composition of the precipitates was identified by the energy dispersive spectroscopy (EDS) probe installed in the FEG-SEM. For each thermal treatment an overall surface fracture of $250 \mu \mathrm{m}^{2}$ was observed to characterize the precipitates. 
Table 3. Heat treatment trials. The heat treatments were performed on a forged bar $250 \mathrm{~mm}$ in diameter.

\begin{tabular}{cccc}
\hline Heat cycle & Heating & Solution Quenching & Aging \\
\hline $2 \mathrm{~T}$ & Temperature: $930^{\circ} \mathrm{C}$ & Air cooling down to room temperature & Temperature: $520^{\circ} \mathrm{C}$ \\
& Holding time: $0.8 \mathrm{~min} / \mathrm{mm}$ & Cooling speed: $0.1{ }^{\circ} \mathrm{C} / \mathrm{s}$ & Holding time: $5 \mathrm{~min} / \mathrm{mm}$ \\
$3 \mathrm{~T}$ & Temperature: $930^{\circ} \mathrm{C}$ & Water quenching down to room temperature & Temperature: $560{ }^{\circ} \mathrm{C}$ \\
& Holding time: $0.8 \mathrm{~min} / \mathrm{mm}$ & Cooling speed: $10^{\circ} \mathrm{C} / \mathrm{s}$ & Holding time: $5 \mathrm{~min} / \mathrm{mm}$ \\
$4 \mathrm{~T}$ & Temperature: $930^{\circ} \mathrm{C}$ & Water quenching down to room temperature & Temperature: $540{ }^{\circ} \mathrm{C}$ \\
& Holding time: $0.8 \mathrm{~min} / \mathrm{mm}$ & Cooling speed: $10^{\circ} \mathrm{C} / \mathrm{s}$ & Holding time: $5 \mathrm{~min} / \mathrm{mm}$ \\
$5 \mathrm{~T}$ & Temperature: $930^{\circ} \mathrm{C}$ & Water quenching down to room temperature & Temperature: $520^{\circ} \mathrm{C}$ \\
& Holding time: $0.8 \mathrm{~min} / \mathrm{mm}$ & Cooling speed: $10^{\circ} \mathrm{C} / \mathrm{s}$ & Holding time: $5 \mathrm{~min} / \mathrm{mm}$ \\
\hline
\end{tabular}

Table 4. Minimum mechanical properties usually required for the application of the A707L5 steel grade.

\begin{tabular}{cccccc}
\hline $\begin{array}{c}\text { Yield strength } \\
{[\mathrm{MPa}]}\end{array}$ & $\begin{array}{c}\text { Ultimate tensile } \\
\text { Strength }[\mathrm{MPa}]\end{array}$ & $\begin{array}{c}\text { Elongation at } \\
\text { fracture point } A[\%]\end{array}$ & $\begin{array}{c}\text { Section reduction } \\
\mathrm{Z}[\%]\end{array}$ & $\begin{array}{c}\text { Hardness } \\
{[\mathrm{HV}]}\end{array}$ & $\begin{array}{c}\text { Absorbed impact energy } \\
\text { at }-100^{\circ} \mathrm{C}[\mathrm{J}]\end{array}$ \\
\hline$>450$ & $>535$ & $>20$ & $>35$ & $170 \div 230$ & $>60$ \\
\hline
\end{tabular}

Table 5. UTS, YS, \%A, \%Z and HV measured for the steel studied as a function of the applied heat treatment (standard deviation in brackets).

\begin{tabular}{ccccc}
\hline & $2 \mathrm{~T}$ & $3 \mathrm{~T}$ & $4 \mathrm{~T}$ & $5 \mathrm{~T}$ \\
\hline UTS & $620 \mathrm{MPa}(10 \mathrm{MPa})$ & $501 \mathrm{MPa}(8 \mathrm{MPa})$ & $529 \mathrm{MPa}(5 \mathrm{MPa})$ & $554 \mathrm{MPa}(5 \mathrm{MPa})$ \\
YS & $493 \mathrm{MPa}(10 \mathrm{MPa})$ & $408 \mathrm{MPa}(13 \mathrm{MPa})$ & $449 \mathrm{MPa}(7 \mathrm{MPa})$ & $457 \mathrm{MPa}(4 \mathrm{MPa})$ \\
$\% A$ & $27.1(2)$ & $32.8(4)$ & $31(2)$ & $31.9(3)$ \\
$\% Z$ & $70.3(2)$ & $79.4(2)$ & $79(3)$ & $78.8(2)$ \\
$\mathrm{HV}$ & $218(10)$ & $177(8)$ & $179(7)$ & $184(8)$ \\
\hline
\end{tabular}

\section{Results}

The change in heat treatment parameters significantly affects the mechanical properties (Tab. 5). The increase in the annealing temperature implies a decrease in yield strength (YS), ultimate tensile strength (UTS) and Vickers micro-hardness (HV). Moreover, all the solution-quenched and aged specimens show lower YS, UTS and HV than the normalized specimen (2T). Only the specimens associated with the conditions $2 \mathrm{~T}$ and $5 \mathrm{~T}$ (the latter with the lowest aging temperature) fit the strength requirement usually imposed by users (Tab. 4). The ductility parameters, i.e. percentage elongation at the fracture point $(\% A)$ and percentage area reduction at the fracture point $(\% \mathrm{Z})$, are compliant with the required parameters for all the applied thermal conditions. The Charpy impact tests showed (Fig. 3) acceptable impact energy values only for the solutionquenched and aged samples (3T, $4 \mathrm{~T}$ and $5 \mathrm{~T}$ ), while a significant drop in the impact energy values are observed for the normalized specimen $(2 \mathrm{~T})$.

The microstructure, provided by the chemical etching, is characterized by the presence of round-shaped perlite and ferrite grains and no other structural constituents (such as martensite or bainite) are identified (Fig. 4). The OM observations also indicate that the grain size is finer in the solutionquenched and aged samples and, quite easy to assess, the lower the aging temperature the finer the grain size.

The base forged steel had an ASTM G index equal to 6.5 that increases up to 8.0 for the normalized sample (2T). The samples that underwent the solution quenching and aging treatment (Tab. 6) show a $G$ index close to 9 , and the finest grain size corresponds to the 5T conditions, that have the lowest aging temperature. Moreover, the volume fraction of the perlite grains decreases significantly as the solution quenching is applied and the aging temperature is lowered (Tab. 6). As expected, the grain refinement promoted by the low temperature aging induces mechanical properties improvement, in particular strength and toughness. Although the elongation $(A \%)$ should be reduced by grain refinement, in this case the slight increase in $A \%$ shown by the $5 \mathrm{~T}$ sample seems more related to the perlite volume fraction decreasing than grain refinement. Thus, the lowest temperature aging seems to improve both the strength and toughness, thanks to grain 
$2 T$

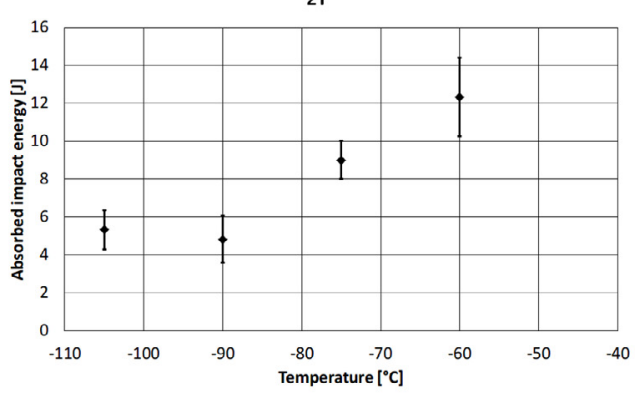

$4 T$

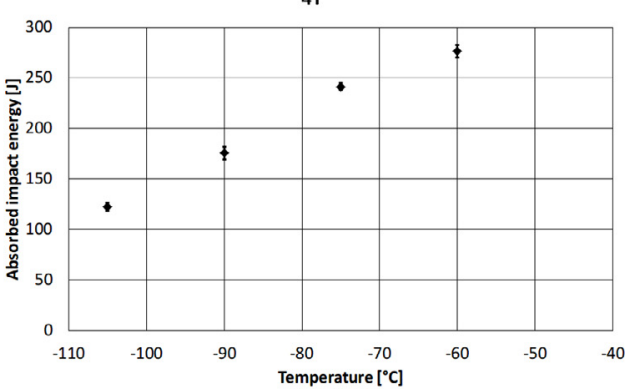

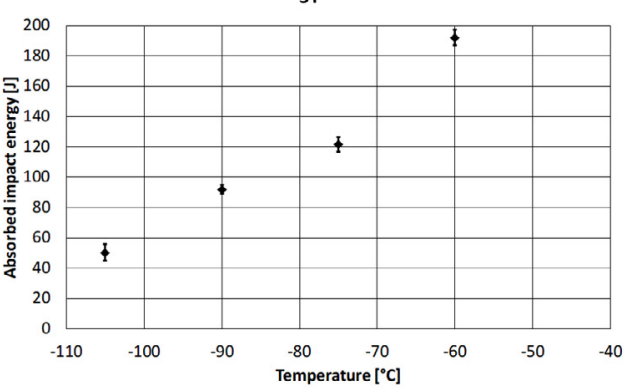

$5 \mathbf{T}$

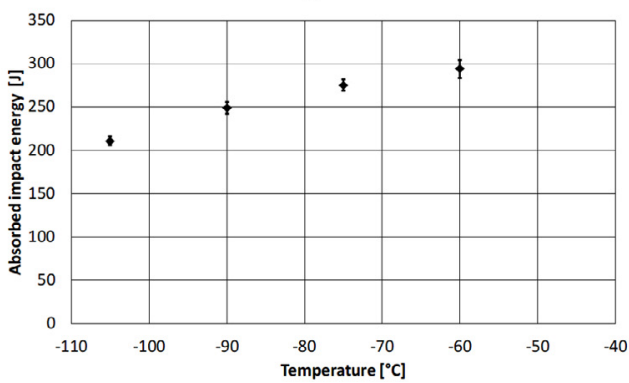

Fig. 3. Absorbed impact energy at different test temperatures as a function of the applied thermal cycle.

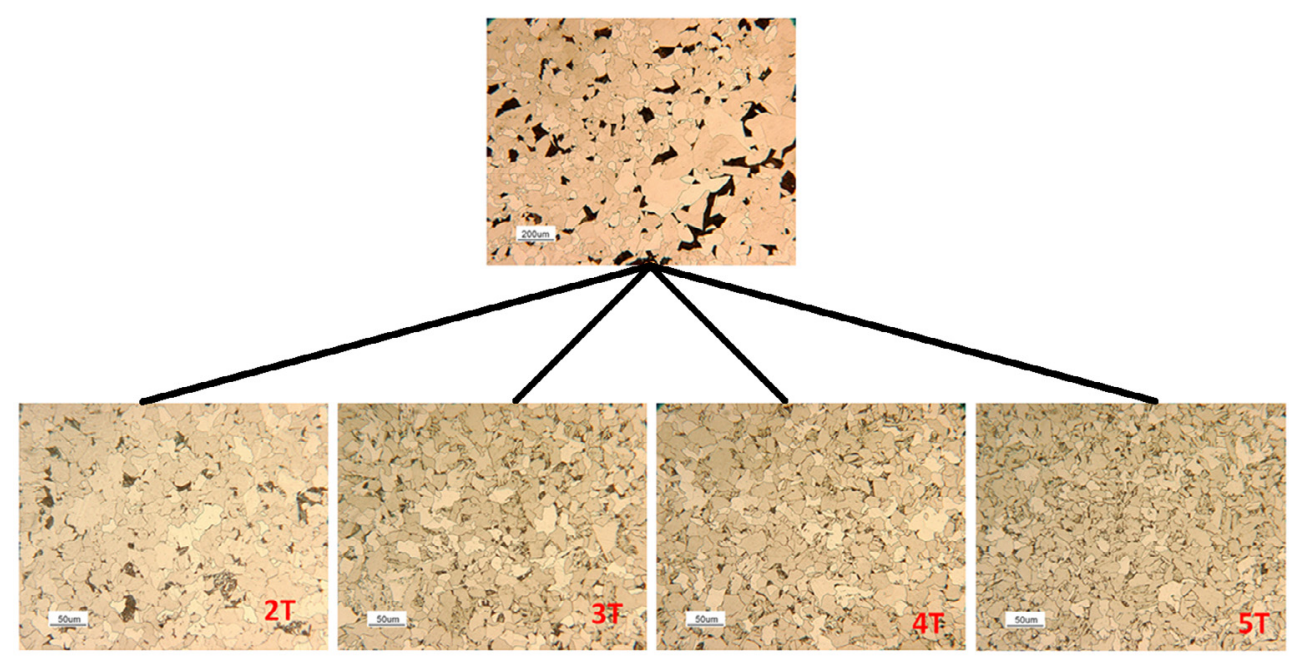

Fig. 4. Microstructure observed in the samples as a function of the different applied heat treatments.

refinement, and also ductility, due to the decrease in the perlite fraction.

The decrease in perlite that manifested after low temperature aging is associated with the lower carbon diffusivity at this thermal level. Actually, the decrease in the aging temperature enhances nucleation phenomena, but also a slowdown of the kinetic growth of perlite. In fact, the carbon during perlite formation diffuses into perlite lamellae, but if the system energy is not enough to promote this diffusion, the perlite grains remain small. This induces a decrease in the overall perlite volume fraction.

The FEG-SEM allows identifying the nano-precipitates. In sample $2 \mathrm{~T}$ rod-like precipitates with an average size (length) up to $450 \mathrm{~nm}$ are observed (Fig. 5a). Sample 3T shows a different morphology and distribution size of the precipitates: the maximum size is about $150 \mathrm{~nm}$ (Fig. 5b); the precipitates ranging from $35 \mathrm{~nm}$ to $150 \mathrm{~nm}$ in length represent $49 \%$ of the overall population and are rod-like precipitates, whereas 
Table 6. Grain size and perlite volume fraction observed in the samples examined as a function of the applied thermal treatment.

\begin{tabular}{cccc}
\hline & ASTM G-Index & Average diameter $(\mu \mathrm{m})$ & Perlite volume fraction $(\%)$ \\
\hline As-forged steel & 6.5 & 37.5 & 10.3 \\
2T & 8.0 & 23.1 & 9.9 \\
3T & 9.0 & 16.2 & 5.1 \\
4T & 9.0 & 14.5 & 4.6 \\
5T & 9.5 & 13.2 & 4.5 \\
\hline
\end{tabular}

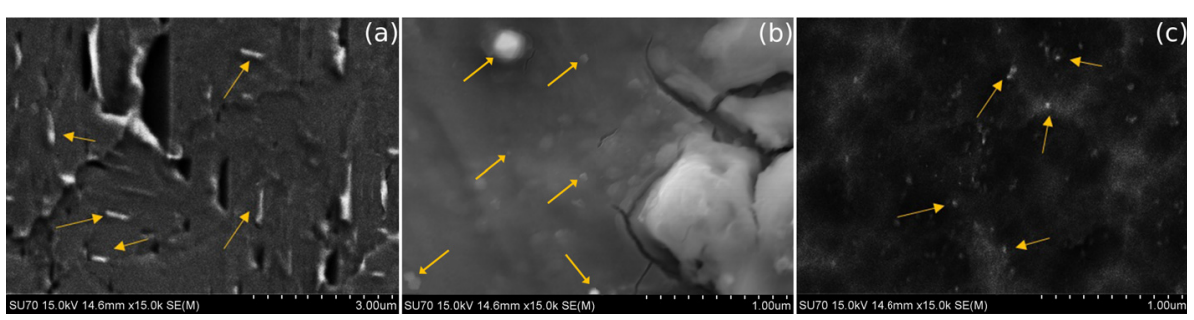

Fig. 5. Example of coarse rod-like precipitates detected in the $2 \mathrm{~T}$ sample (a); spherical precipitates detected in the 3T sample (b) and small spherical precipitates detected in the 5T sample (c).

Table 7. Typical chemical composition of the identified intermetallic precipitates by EDS probe ( $\%$ weight concentration).

\begin{tabular}{ccccc}
\hline \% wt. & $\mathrm{Fe}$ & $\mathrm{Ni}$ & $\mathrm{Cu}$ & $\mathrm{Mn}$ \\
\hline 2T & 9.4 & 1.2 & 79.2 & 10.2 \\
3T & 7.2 & 0.7 & 82.3 & 9.8 \\
4T & 8.3 & 0.3 & 81.5 & 9.9 \\
5T & 8.2 & 0.1 & 83.2 & 8.5 \\
\hline
\end{tabular}

$51 \%$ of the round-shaped precipitates are in the range of 20-35 $\mathrm{nm}$ (diameter). The $4 \mathrm{~T}$ sample has $38 \%$ of rod-like precipitates ranging from $35 \mathrm{~nm}$ to $150 \mathrm{~nm}$, whereas the remaining fraction $(62 \%)$ is round precipitates smaller than $35 \mathrm{~nm}$. Finally, the 5T sample has $27 \%$ of rod-like precipitates with a size ranging between $30 \mathrm{~nm}$ and $130 \mathrm{~nm}$ and the other precipitates $(73 \%)$ have a round morphology smaller than $35 \mathrm{~nm}$ (Fig. 5c). The analysis performed by FEG-SEM did not allow identifying the crystallographic features of the precipitates observed, but the chemical composition allows recognizing these precipitates as copper compounds (Tab. 7). The measured average chemical composition and the observed morphology are the same ones identified by Zhang et al. [7-10] as $\varepsilon$-Cu precipitates.

\section{Discussion}

The 2T (normalized and aged) samples show the highest UTS, YS and HV values and high ductility properties associated with poor toughness performances. The highest strength performances are due to the highest volume fraction of the formed perlite, if compared with the solution-quenched and aged samples, while the most significant ductility properties are associated with the largest grain size among the observed microstructures. On the other hand, the large grains are also responsible for the low impact energy absorbed during the Charpy tests. The solution-quenched and aged specimens have a lower volume fraction of perlite, but the refining of the grain size induces an increase in the strength properties, causing grain boundary strengthening. Such an effect becomes particularly evident as the tempering temperature is lowered, and actually it reaches a maximum effect for the $5 \mathrm{~T}$ samples. The grain size refinement is associated with the precipitation of the $\varepsilon$-Cu precipitates, because copper does not form any intermetallic compound with iron [11,12]. The grain size in the presence of some pinning precipitates is ruled by the following relation [13]:

$$
d_{\max }=\frac{4}{3} \frac{r_{\text {prec }}}{f_{\text {prec }}}
$$

where $d_{\max }$ is the limiting grain size, $r_{\text {prec }}$ is the radius of the pinning precipitates and $f_{\text {prec }}$ is the volume fraction of the precipitates. The $\varepsilon-\mathrm{Cu}$ precipitates have a finer size in $4 \mathrm{~T}$ 
and 5T samples than in 2T and 3T samples. The pinning effect promoted by the smallest $\varepsilon$-Cu precipitates is consistent with the conditions imposed by Equation (1), since the finer the precipitates the more effective the pinning effect is on grain growth. The $2 \mathrm{~T}$ specimens have coarse $\varepsilon$-Cu precipitates due to the high temperature permanence (provided by the normalization) that promotes the precipitate growth at the expense of the nucleation stage. On the contrary, the solution quenching followed by the aging treatment promotes a fine and well-dispersed nucleation of the precipitates at the expense of the precipitate growth. The finest precipitation and the consequent optimal combination of mechanical performances (in terms of strength and toughness) were observed for the solution-quenching and aging treatment performed at $520^{\circ} \mathrm{C}$ (5T conditions).

The measurements of the chemical composition featuring the precipitates suggest that the diffusion of $\mathrm{Cu}$ and $\mathrm{Fe}$ is favored (if compared with $\mathrm{Ni}$ and $\mathrm{Mn}$ diffusion) during the aging treatment performed at the lowest temperatures and this implies a dilution of Mn and Ni content in the spherical and small precipitates observed in specimens treated by the $5 \mathrm{~T}$ cycle. Actually, the diffusion coefficient of $\mathrm{Cu}$ in $\alpha$-Fe is $30 \%$ higher than that of $\mathrm{Ni}\left(D_{\mathrm{Cu}-\alpha-\mathrm{Fe}}=3.52 \times 10^{-20} \mathrm{~m}^{2} / \mathrm{s}\right.$; $D_{\mathrm{Ni}-\alpha-\mathrm{Fe}}=2.70 \times 10^{-20} \mathrm{~m}^{2} / \mathrm{s}$ at $520{ }^{\circ} \mathrm{C}$ ) [14].

The finer the pinning precipitates, the lower the final grain size. Hornbogen et al. [15] and Zhang et al. [10] studied the precipitation of $\mathrm{Cu}$-rich phases in $\alpha$-Fe and they found that $\varepsilon$-Cu precipitates at the nucleation stage consist of bcc (body-centered cubic) elementary cells that are converted into a fcc (face-centered cubic) phase constituting spherical particles larger than 30$35 \mathrm{~nm}$. The application of the highest aging temperature induces a coarsening of the precipitates and a decrease in the thermodynamic driving force for the precipitation (that decreases $f_{\text {prec }}$ ), and so a high aging thermal level causes a consequent increase in the grain size. The observed growth mechanism of the copper precipitates shows a transition of the $n$ coefficient of the JMAK relation (Eq. (2)):

$$
X_{V}=1-\exp \left(k t^{n}\right)
$$

where $X_{V}$ is the precipitated fraction, $k$ is the reaction rate constant, $t$ is the time and $n$ is the kinetic exponent. The transition of the precipitates from a round-shaped growth to rod-like shape implies a decrease in the $n$ coefficient from a maximum of 3-4 down to a minimum of $1-2$, indicating a decrease in the kinetic growth as the aging time increases [16]. On the other hand, the shape variation observed in the precipitates could also depend on the $k$ parameter and/or could consequently modify it.

The dual effect of grain size and precipitated particles on strengthening can be analytically determined by applying the well-known Hall-Petch and Ashby-Orowan approaches [17-21]. To determine the increment in yield strength associated with grain refinement, the $k_{y}$ coefficient of the HallPetch equation was determined by applying the relation formulated by Takeda et al. [22] for low-carbon steel, whereas the precipitate influence was taken into account by applying the coefficient proposed by Gladman for steel and iron alloys to the Ashby-Orowan equation [23, 24]. The Gladman approach was chosen because it provides better results, as demonstrated by Carsì et al. [25]. The calculation indicates that in the case of the $2 \mathrm{~T}$ sample, the contribution of precipitates accounts for nearly $50 \%$ of the total yield increment, whereas for the solutionquenched and aged samples, the predominance of grain refinement was detected, ranging from $65 \%$ (3T sample) to $80 \%$ (5T sample). The results obtained for solutionquenched samples are consistent with the literature, since it was estimated by Irvine et al. that for a low-carbon steel, the grain size effect on tensile properties accounts for over $50 \%[26,27]$.

\section{Conclusions}

On the basis of the experimental trials and observations, the following conclusions can be made:

- the steel does not assume a martensite structure even after the application of a quenching treatment;

- the applied quenching covers the role of a solution quenching treatment; 
- the optimal combination between the yield stress and toughness can be achieved by the control of the grain size: the lower the grain size, the higher the yield stress and the toughness;

- the absorbed impact energy and the toughness increase as the volume fraction of the perlite grain decreases;

- the solution quenching treatment limits the perlite volume fraction;

- the increase in the yield stress is ruled by the $\varepsilon-\mathrm{Cu}$, whose shape and size are controlled by the cooling rate and aging temperature;

- the quenching solution treatment is needed to avoid the precipitation of coarsened intermetallic precipitates;

- the aging time has to be performed at the lowest possible thermal level (i.e. $520^{\circ} \mathrm{C}$ ) in order to ensure a high volume fraction of fine precipitates, with fine size $(<35 \mathrm{~nm})$ and round shapes;

- an excessive temperature of the aging treatment induces the change in the growth mechanism and the $n$ coefficient of the JMAK model changes from 3-4 down to $1-2$, that is associated with the formation of coarse rod-like precipitates, causing a decrease in the strength and toughness due to an increase in the grain size.

Finally, the 5T sample reached the best compromise between tensile properties and toughness, satisfying all the minimum requirements for A707-L5 application.

Since not only the temperature affects precipitation, grain growth and other metallurgical processes, the effect of the aging time should be investigated, in order to define the best operative conditions for industrial application.

\section{References}

[1] Q.-D. Liu, J.-F. Gu, C.-W. Li, J. Mater. Res. 29 (2014) 950-958

[2] A.J. Craven, K. He, L.A.J. Garvie, T.N. Baker, Acta Mater. 48 (2000) 3857-3868

[3] M. Charleux, W.J. Poole, M. Militzer, A. Deschamps, Metall. Mater. Trans. A 32 (2001) 1635-1647

[4] M.A. Walsh, S. Price, ASTM Special Technical Publ. 1259 (1997) 196-209
[5] H.R. Habibi, Atomic structure of the $\mathrm{Cu}$ precipitates in two stages hardening in maraging steel, Center for University Research on Aluminum (CURAL), Dept. of Applied Sciences, University of Quebec at Chicoutimi, University Blvd., Chicoutimi, Quebec, Canada, 2005

[6] A. Ghosha, S. Das, S. Chatterjee, Ageing behavior of a Cu-bearing ultrahigh strength steel, Department of Mechanical Engineering, University of Nevada, Las Vegas (UNLV), United States; Department of Metallurgy and Materials Engineering, Bengal Engineering and Science University, Shibpur, India; MTC Division, National Metallurgical Laboratory, Jamshedpur, India, 2007

[7] L. Ren, L. Nan, K. Yang, Mater. Design 32 (2001) 2374-2379

[8] S.H. Chen, M.Q. Lu, J.D. Zhang, J.S. Dong, K. Yang, Acta Metall. Sinica 40 (2004) 314-318

[9] S.W. Thompson, G. Krauss, Metall. Mater. Trans. A 27 (1996) 1573-1588

[10] Z. Zhang, G. Lin, Z. Xu, J. Mater. Sci. Technol. 24 (2008) 775-780

[11] K.C. Hari Kumar and V. Raghavan, Journal of Alloy Phase Diagrams 5 (1989) 201-220.

[12] C. Servant, M. Guymont, O. Lyon, Scripta Materialia 45 (2001) 103-108

[13] B.C. De Cooman, J.G. Speer, I.Y. Pyshmintsev, N. Yoshinaga, Materials Design. The Key to Modern Steel Products, GRIPS Media (ed.), Bad Harzburg (Germany), 2007, p. 284

[14] B.C. De Cooman, J.G. Speer, I.Y. Pyshmintsev, N. Yoshinaga, Materials Design. The Key to Modern Steel Products, GRIPS Media (ed.), Bad Harzburg (Germany), 2007, p. 4

[15] E. Hornbogen, R.C. Glenn, Trans. Metall. Soc. AIME 218 (1960) 1064-1070

[16] B.C. De Cooman, J.G. Speer, I.Y. Pyshmintsev, N. Yoshinaga, Materials Design. The Key to Modern Steel Products, GRIPS Media (ed.), Bad Harzburg (Germany), 2007, p. 90

[17] W.F. Smith, J. Hashemi, Foundations of materials science and engineering, 3rd edition, McGraw-Hill, New York (NY), 2006, pp. 242243

[18] E.O. Hall, Proc. Phys. Soc. London 64 (1951) 747-753

[19] N.J. Petch, J. Iron Steel Instit. London 173 (1953) 25-28 
[20] E. Orowan, Proceedings of International Stresses in Metals and Alloys, Inst. Metals, London, 1948, $451 \mathrm{p}$.

[21] M.F. Ashby, Oxide dispersion strengthening, G.S. Ansell et al. (eds.), Met. Soc. AIME, Warrendale (PA), 1958, pp. 143-205

[22] K. Takeda, N. Nakada, T. Tsuchiyama, S. Takaki, ISIJ Int. 48 (2008) 1122-1125

[23] T. Gladman, The physical metallurgy of microalloyed steels, Inst. Metals, London, 1997, $52 \mathrm{p}$.
[24] Y. Li, J.A. Wilson, A.J. Craven, P.S. Mitchell, D.N. Crowther, T.N. Baker, Mater. Sci. Technol. 23 (2007) 509-518

[25] M. Carsí, F. Penalba, I. Gutiérrez, J. Mater. Sci. 28 (1993) 6450-6456

[26] K.J. Irvine, F. Pickering, T. Gladman, J. Iron Steel Instit. London 205 (1967) 161-182

[27] H.K.D.H. Bhadeshia, R.W.K. Honeycombe, Steels: Microstructure and properties, 3rd edition, Butterworth-Heinemnn, Oxford (UK), 2006, 69 p. 